\title{
VARIABILIDAD DEL DERECHO NATURAL Y RETENCIÓN DE LAS INDIAS
}

\author{
THE VARIABLE CHARACTER OF NATURAL RIGHT AND THE \\ RETENTION OF THE INDIES
}

\author{
Joaquín García-Huidobro* \\ José A. POBLete
}

\begin{abstract}
RESUMEN: Hay un aspecto de la famosa disputa que tuvo lugar en los siglos XVI y XVII sobre los justos títulos, que no ha recibido un adecuado tratamiento filosófico. Se trata de la posibilidad de que, en caso de que la conquista hubiese sido injusta, hubiese algún título que permitiera o incluso obligara a la Corona a retener esas tierras. En este artículo se muestra la forma en que este tema fue abordado por Vitoria, el Licenciado Falcón y Solórzano Pereira. El argumento de estos autores, inspirado en la idea aristotélica de que lo justo natural está sujeto a cambio, es que, incluso si se hubiese hecho en contra de la justicia, el abandono de las Indias traería consigo para los nativos más daños que beneficios. Por lo mismo, la potencial obligación de restituir las tierras conquistas cesaría o, al menos, quedaría en suspenso mientras la situación no cambiara sustantivamente.
\end{abstract}

Palabras clave: Justos Títulos; Francisco de Vitoria; Solórzano Pereira; Licenciado Falcón; Derecho Natural.

ABSTRACT: There is one aspect of the famous 16th and 17th centuries dispute on the 'Just Titles' (justos títulos) which has not yet received proper philosophical analysis by scholars, namely: the possibility that, in the case that the Spanish occupation had been unjust, there still remains a title which would allow -or even force- the Crown to retain those lands. This article focuses on the approach to this issue by the Dominican Francisco de Vitoria, the Licenciado Francisco Falcón and the jurist Juan de Solórzano Pereira. Their argument, grounded on the Aristotelian claim that things that are just by nature are subject to change, states that, even if unlawfully acquired, the abandon of the Indies would certainly bring about more damage than benefits to the natives. Thus, the potential duty to restitute the conquered lands would either cease or, at least, be suspended while the situation remains the same.

Keywords: Just Titles; Francisco de Vitoria; Solórzano Pereira; Licenciado Falcón; Natural Law.

\footnotetext{
Doctor en Filosofía por la Universidad de Navarra y Doctor en Derecho por la Universidad Austral, Argentina. Profesor titular del Instituto de Filosofía de la Universidad de los Andes, Chile. Código Orcid 0000-00029958-8566. Dirección postal: Av. Monseñor Álvaro del Portillo 12455, Santiago, Chile. Correo electrónico: jgh@miuandes.cl. Esta investigación forma parte del proyecto Fondecyt 1191194 "Universalidad y singularidad en el mundo virreinal. Elementos para una filosofía del Derecho Indiano". Los autores agradecen el apoyo recibido en el Max-Planck-Institut für Rechtsgeschichte und Rechtstheorie como también en el de Nicola Center for Ethics and Culture de la Universidad de Notre Dame.

** Doctor en Filosofía por la Universidad de los Andes, Chile. Miembro posdoctoral del Grupo de Investigación en Filosofía Práctica del Instituto de Filosofía de la Universidad de los Andes, Chile. Código Orcid 00000001-6723-6550. Dirección postal: Av. Monseñor Álvaro del Portillo 12455, Santiago, Chile. Correo electrónico: japoblete@miuandes.cl.
} 


\section{INTRODUCCION}

La controversia de los justos títulos en el proceso de conquista y evangelización de las Indias tuvo dos vertientes, de las cuales una sola suele acaparar la atención de los estudios contemporáneos. Por una parte, se debatió si los reyes de España podían desplegar labores de conquista de manera legítima, e incluso hacer la guerra a los indios que ofrecieran resistencia. Por otra, se discutió si asistían justos títulos a los reyes, no ya respecto de la adquisición de las tierras, sino de su retención. Este último tema ocupó la atención de Francisco de Vitoria (ca. 1483-1546) en su Relectio de Indis (RI), dictada en 1539'1 , aunque solo de manera tangencial, porque su atención primordial fue puesta en la cuestión de la adquisición. Como es sabido, su trabajo se limita sobre todo a demostrar la injusticia de ciertos títulos, por entonces esgrimidos para justificar la Conquista, y ofrecer otros más ajustados al derecho natural.

Sin que el tema de la adquisición jamás perdiera del todo relevancia, la cuestión de la retención fue poco a poco acaparando la atención de los participantes en la controversia. La razón es histórica. Con el paso del tiempo, no solo aumentaba entre los indios el número de bautizados (y, por tanto, de cristianos libres), sino que las propias culturas del Viejo y el Nuevo Mundo se volvían cada vez más dependientes la una de la otra. Esto explica el hecho de que figuras como el licenciado Francisco Falcón (1521-1587) o el famoso jurista Juan de Solórzano Pereira (1575-1655), enfrentados a la "duda indiana", hiciesen un enorme esfuerzo por aclarar la justa retención de las tierras conquistadas. Para ese entonces, a más de cien años del descubrimiento de América, el problema moral de la adquisición de esos dominios cedía en importancia ante una pregunta política más apremiante: incluso en el caso de que la ocupación de las Indias hubiese sido injusta, ¿estaría por ello la Corona obligada abandonarlas?

En las páginas que siguen, estudiaremos uno de los justos títulos invocados por los participantes de la contienda De indiis para justificar la retención de las Indias por parte de la Corona de Castilla y León. De acuerdo con este título, puede afirmarse que, no obstante una eventual injusticia en la ocupación de las Indias, resulta imposible restituir dichos dominios a los nativos, pues las relaciones entre indios y españoles se encontrarían a tal punto entrelazadas que no podrían aquellos ser abandonados por estos sin grave daño para ambos. Se trata de un argumento que se volverá transversal a los autores de la Escuela de Salamanca que tomaron parte en esta disputa ${ }^{2}$.

Nuestra tesis consiste en mostrar que este título no es ni un recurso oportunista, ni un artilugio jurídico, ni tampoco una muestra de lo que algunos autores modernos han calificado de "maquiavelismo teológico", un peculiar iusnaturalismo que en la práctica implica negar los criterios de la guerra justa ${ }^{3}$. Por el contrario, más allá del juicio que merezca esta doctrina, el argumento de Vitoria y de quienes lo siguieron en Indias se basa en una tradición filosófica y jurídica de larga data. Como veremos, su razonamiento recurre a

\footnotetext{
RDI, I, 3, 17.

2 Cf. Baciero (1994) III 5, 29-39.

3 Castañeda (2006) pp. 122-123.
} 
la antigua tesis aristotélica, según la cual aquello que es justo por naturaleza está sujeto a cambio (EN V, 7 1134b18-35a5). Se trata de una idea ampliamente comentada entre los académicos que tomaron parte en el renacimiento aristotélico del siglo XIII, y que adquirió una particular actualidad y relevancia política en los siglos XVI y XVII.

Para mostrar esto, expondremos primero los puntos fundamentales en los que se sostiene la tesis de Aristóteles sobre la condición cambiante del derecho natural, y su posterior recepción medieval (I); luego, presentaremos la argumentación de Francisco Vitoria, del procurador de indios Francisco Falcón y de Juan Solórzano de Pereira, para mostrar hasta qué punto su razonamiento descansa sobre la tesis aristotélica antedicha (II); finalmente, nos haremos cargo de algunas críticas actuales que ha recibido el argumento de Solórzano en este punto (III).

\section{LA CONDICIÓN CAMBIANTE DEL DERECHO NATURAL}

El alegato de que resulta imposible restituir los reinos al margen de la justicia de la adquisición fue compartido por todos los autores de la época ${ }^{4}$, y refleja una idea de fondo de gran relevancia filosófica. Como veremos, cuando un bien ha sido adquirido por medios injustos, normalmente la restitución constituye una obligación moral natural 5 . Insistir, por tanto, en que las Indias no deban ser restituidas, incluso habiendo mediado injusticia en su adquisición, equivale a decir en tomismo de buena ley que aquello que es justo por naturaleza ha mutado.

Con todo, la idea de que lo justo natural está sujeto a cambio no es una invención del Siglo de Oro español. Se trata de una tesis aristotélica que, merced a las nuevas traducciones latinas de Ethica Nicomachea en los siglos XII y XIII ${ }^{6}$, fue comentada por los más influyentes pensadores medievales, antecedentes ideológicos directos de quienes tomar parte en las polémicas político-jurídicas de Indias. Sin duda, el desarrollo más pormenorizado de esta doctrina de Aristóteles se encuentra en el libro V de la Ética, donde el Estagirita obra

\footnotetext{
4 Por todos: Acosta, De promulgando evangelio apud barbaros sive De procuranda indorum salute, Libri sex, 125-26 Lib. II, cap. XI; Matienzo, Gobierno del Perú, 16 Lib. I, cap. III. Un resumen de las afirmaciones de los autores anteriores a Solórzano en DII III, 5, 1-3. Cf. BaCIERo (1994) pp. 99-102.

5 Cf. JANSEn (2012).

${ }^{6}$ La primera traducción Ethica Nicomachea al latín, y que marca su entrada en el medioevo, fue la traducción fragmentaria de BuRgundio DE PISA. Por razones que se desconocen, el traductor pisano fue haciendo entrega de los diversos libros en forma separada. En 1246, el obispo de Lincoln y canciller de Oxford RoBERTO Grosseteste publica por primera vez una traducción latina de la integridad del trabajo aristotélico. Esto marca, en palabras de R.A. Gauthier, el inicio del así llamado "reinado de la Ética a Nicómaco". GauthiER y Jolif (1970) p. 120. Es de notar el enorme influjo que tuvo esta obra en el pensamiento jurídico del medioevo occidental. Antes de que las traducciones la volviesen visible ante filósofos y teólogos latinos, la teoría sobre la justicia era bastante precaria, y descansaba significativamente sobre premisas de naturaleza teológica, muchas de ellas de poco interés: Odon LotTin (1974) pp. 298-299; Fuchs (2007) p. 74-75. La recepción de la ética aristotélica supuso un enriquecimiento invaluable en este ámbito, en el marco de lo cual cabe mencionar el desarrollo y estudio de la distinción entre justicia distributiva y conmutativa, o la virtud de la epiéikeia que se ordena al ajuste de leyes universales a casos extraordinarios que caen fuera de ella.
} 
su conocida distinción entre lo que es justo por naturaleza y lo que es justo por ley ${ }^{7}$. Dice Aristóteles: "De lo justo en la comunidad política, una [forma] es natural y otra por ley . Es natural la que tiene en todas partes la misma fuerza, y no porque [a los hombres] les parezca bien o no; es, en cambio, por ley la que en principio es indiferente que sea de esta o de aquella manera, pero deja de ser indiferente una vez que se la establece"

Luego de ofrecer algunos ejemplos ilustrativos de lo justo legal, Aristóteles abre una discusión con un grupo de filósofos contemporáneos suyos, los sofistas, quienes negaban la existencia de una justicia natural. Para ellos, lo natural no está sujeto a cambio, mientras que resulta evidente la mutación de las cosas justas; por lo mismo, concluyen, no pueden existir cosas justas por naturaleza. La respuesta de Aristóteles puede parecernos sorprendente -y ciertamente lo fue para los autores del medioevo-, pues contrariamente a lo que cabría esperar no niega la segunda premisa del argumento sofista, esto es, que las cosas justas estén sometidas a variabilidad. El filósofo más bien rechaza el carácter inmutable de aquello que es natural (la primera premisa) ${ }^{9}$. De hecho, unas pocas líneas más abajo afirma expresamente la condición cambiante de lo justo natural:

"Cuáles, entre las cosas que pueden ser de otra manera, son [justas] por naturaleza y cuáles no lo son [por naturaleza] sino por ley, esto es, por convención, es algo evidente, aun cuando unas y otras son igualmente mudables" 10 .

Santo Tomás de Aquino, antecedente directo de los teólogos de Salamanca y de las principales figuras del pensamiento jurídico del Siglo de Oro, comenta en detalle la respuesta de Aristóteles a los sofistas. A propósito del texto donde el filósofo griego afirma la condición cambiante de lo justo natural, señala el Aquinate:

"Todas las cosas justas a veces parecen estar sujetas al cambio: en efecto, nada parece ser más justo que se devuelva al depositante su depósito y, sin embargo, no se debe devolver su depósito al enajenado que reclama su espada [entregada en depósito], ni al traidor a la patria que reclama su dinero para adquirir armas"11.

Poco más adelante, precisa el alcance de esta clase de cambio:

\footnotetext{
7 En la misma línea discurre el pasaje del Eutifrón donde Platón distingue entre pensar que una acción es "pía" (que es la justicia con los dioses) porque es agradable a los dioses y pensar que una acción es agradable a los dioses porque es pía (10e-11b). A diferencia de los que pensaba su interlocutor, para Sócrates una acción impía no es injusta debido a que los dioses la odien y prohíban, sino que los dioses odian y prohíben una determinada acción por causa de que es impía e injusta. TOMÁs DE AQUiNo recoge esta idea en textos como ST II-II, 57, 2 ad 3.

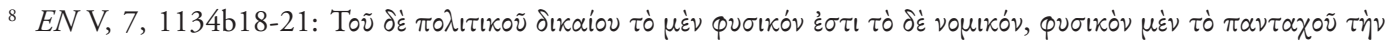

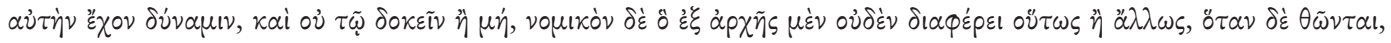

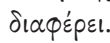

9 El aparente desajuste entre esta doctrina y las concepciones temprano-medievales sobre la ley natural probablemente contribuyó a que el traductor inglés, ROBERTo GROSSETESTE, alterara significativamente el pasaje aristotélico. Asimismo, existe suficiente evidencia para asegurar que la influencia que ejercieron estas alteraciones en la primera etapa de las recepción del pasaje en Occidente latino fue sustantiva desde un punto de vista filosófico.

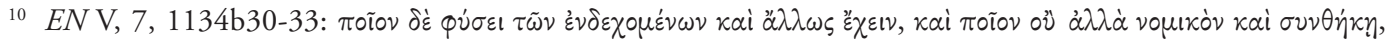

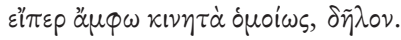

11 SLE 306: 147-152: omnia iusta videntur aliquando esse mota. Nibil enim videtur esse magis iustum quam quod deponenti depositum reddatur; et tamen non est reddendum depositum furioso reposcenti gladium vel proditori patriae reposcenti pecunias ad arma.
} 
"Las cosas que son naturales para nosotros son, en efecto, del mismo modo en la mayoría de los casos (ut in pluribus), aunque fallan en unos pocos (ut in paucioribus) [...]; así, también aquellas cosas que son naturalmente justas como, por ejemplo, que el depósito debe ser devuelto, en la mayoría de los casos deben observarse, aunque en unos pocos cambian"12.

El ejemplo del depósito, originario de Platón ${ }^{13}$, recurrente en la obra del Aquinate, es recogido por la tradición medieval posterior ${ }^{14}$. De hecho, santo Tomás se apropia del ejemplo (y, por supuesto, de la doctrina aristotélica en que se sustenta), y lo hace suyo en un pasaje fundamental para la cuestión que tratamos aquí, a saber, el artículo de Summa Theologiae en que se pregunta si la ley natural es la misma para todos (ST I-II, q. 94, a. 4). En su respuesta, Tomás hace una distinción. En cuanto a los primeros principios, señala, la ley natural es siempre la misma para todos; pero en cuanto a las conclusiones que se siguen de los primeros principios, su verdad o rectitud no parece ser igual en todos: "Para todos es recto y verdadero esto, a saber: que hay que obrar según la razón. Sin embargo, de este principio se sigue una suerte de conclusión particular: que las cosas dadas en depósito deben ser devueltas. Y esto, efectivamente, es verdadero en la mayoría de los casos (ut in pluribus), pero en algún caso podría suceder que sea dañoso (damnosum) y, por consiguiente, irracional, que las cosas depositadas fuesen devueltas; como, por ejemplo, si alguien pidiese [el depósito] para combatir a la patria"15.

En este pasaje, Tomás hace explícita la razón que subyace a la idea de que la obligación natural de devolver los depósitos esté sujeta a cambio: en algún caso, la devolución podría volverse algo perjudicial (damnosum) y, por tanto, irracional. En otras palabras, el argumento plantea que la obligación de devolver el depósito (como toda obligación natural de hacer) está sujeta a una condición: si su observancia es contraria a las exigencias de la razón, porque de ella se siguen más males que bienes, entonces no debe ser cumplida. Obviamente, esto no debería ocurrir sino de modo excepcional (ut in paucioribus) pues, en la mayoría de los casos (ut in pluribus), la obligación conserva todo su vigor ${ }^{16}$. En síntesis, respecto de aquellos preceptos afirmativos de la ley natural que son como conclusiones más particulares de los primeros principios, su fuerza obligatoria estará sujeta a la condición de

12 SLE 306: 187-189; 194-196: Ea enim quae sunt naturalia apud nos sunt quidem eodem modo ut in pluribus, sed ut in paucioribus deficiunt; [...] ita etiam et ea quae sunt naturaliter iusta, utputa depositum esse reddendum, ut in pluribus est observandum, sed ut in paucioribus mutatur.

13 Rep. 331c.

14 Esta doctrina tomista influyó en muchos comentadores medievales de la Ética: BuRLEY, Burleus Super libros Ethicorum. Habes in hoc uolumine candidissime lector Gualtieri Burlei expositionem super decem libros Ethicorum Aristotelis, 95 col. I; Odonis, Expositio in Aristotelis ethicam, V, q. 15, lectio XII, fol 109b; Oresme, Le livre de Ethiques d'Aristote, nota n. 8, 304.

15 ST I-II, q. 94, a. 4, c.: Apud omnes enim hoc rectum est et verum, ut secundum rationem agatur. Ex hoc autem principio sequitur quasi conclusio propria, quod deposita sint reddenda. Et hoc quidem ut in pluribus verum est, sed potest in aliquo casu contingere quod sit damnosum, et per consequens irrationabile, si deposita reddantur; puta si aliquis petat ad impugnandam patriam.

16 El razonamiento forma parte también de los artículos subsiguientes. Así, SANTO TomÁs señala en ST I-II, q. 94, a. 5, c.: "Quantum autem ad secunda praecepta, quae diximus esse quasi quasdam proprias conclusiones propinquas primis principiis, sic lex naturalis non immutatur quin ut in pluribus rectum sit semper quod lex naturalis habet. Potest tamen immutari in aliquo particulari, et in paucioribus, propter aliquas speciales causas impedientes observantiam talium praeceptorum, ut supra dictum est"; cf. también ST I-II, q. 94, a. 6, c. 
que de su cumplimiento no se sigan mayores males que bienes. Por el contrario, si de la observancia de alguno de estos preceptos se siguen más males que bienes -cuestión que, como vimos, solo ocurriría por excepción-, estos perderían su fuerza obligatoria.

Ahora bien, este recurso al principio del mal menor no supone en modo alguno una concesión a una suerte de proporcionalismo. Son muchos los textos que atestiguan un uso extendido de él por parte de autores que van desde Sócrates a Tomás de Aquino, pasando por Aristóteles, Cicerón, Agustín, y otros de la patrística latina y griega. Y sin embargo, toda esta tradición coincide en que este no puede ser el principio último para resolver toda la justicia de un acto humano ${ }^{17}$. Lo que hace una teoría de la ley natural como la de Tomás de Aquino -que es como el correlato gnoseológico y descendente de lo que, mirado desde una óptica ontológica y ascendente, es en realidad una ética de las virtudes- es situar la operación del principio del mal menor en su ámbito propio, sin pretender de este criterio ni más ni menos de lo que corresponde. Y así, a pesar de que Tomás reconoce que lo justo por naturaleza es cambiante (variabilidad que en Summa Theologiae, tratando sobre la ley natural, restringe solo al caso de los preceptos secundarios [ST I-II, q. 94, a. 4, ad 2.]), no deja de apuntar que las razones esenciales (rationes) de las cosas cambiantes son ellas mismas inmutables: "est tamen attendendum quod, quia rationes etiam mutabilium sunt immutabiles, [...]" (SLE 306: 197-98). Si un acto (como, por ejemplo matar) recae sobre una 'materia indebida' (materia indebita; como, por ejemplo, un ser humano inocente), se trata de un acto contrario a la esencia de una virtud (en este ejemplo, a la virtud de la justicia), pues destruye algunos de sus elementos esenciales (en este ejemplo, el acto de la justicia de dar a cada uno lo suyo, que en el caso del inocente es el abstenerse de intentar directamente su muerte). Actos de esta clase son actos siempre malos, intrínsecamente malos, al margen de las circunstancias en que se concrete, y sin perjuicio del móvil intencional ulterior, por más bueno que sea. En consecuencia, poco después de mencionar el ejemplo del depósito para ilustrar el carácter variable de lo justo natural, el Aquinate restringe esta noción asegurando que: "aquellas cosas que pertenecen a la esencia misma de la justicia en modo alguno pueden mutar como, por ejemplo, que no se debe robar, lo cual es hacer lo injusto"18.

Ahora bien, a pesar de la enorme influencia de su comentario, santo Tomás es más bien un transmisor de las ideas de su maestro san Alberto Magno, quien comentó en dos

\footnotetext{
17 En la dogmática moderna, encontramos autores que sí le atribuyen tal función al principio del mal menor. Se trata de académicos que interpretan el principio desde una óptica consecuencialista o proporcionalista. Para ellos, como explica Miranda, podría ser lícito, por ejemplo, matar intencionalmente a un ser humano inocente para salvar a un número superior de personas Miranda (2017) p. 214. Es así que algunos autores proporcionalistas están dispuestos a conceder que, para ellos, el principio del mal menor constituye algo así como "regla de oro" del razonamiento moral: "todas las reglas y distinciones concretas -explica el proporcionalista RicHARD MCCORMICK- son subsidiarias a esta, y son válidas, por consiguiente, en la medida en que ellas en realidad nos lleven a lo que de hecho es el mal menor" McCormick (1978) p. 38.

18 SLE 307: 203-5: “illa quae pertinent ad ipsam iustitiae rationem nullo modo possunt mutari, puta non esse furandum, quod est iniustum facere". Otro tanto señala en la Suma Teológica, donde afirma que lo natural sería inmutable siempre y en todas partes solo en el caso de un ser dotado de una naturaleza inmutable, "pero la naturaleza humana es mudable, y, por consiguiente, lo que es natural al hombre puede en algunos casos fallar", como sucede en el caso del depósito (natura auten hominis est mutabilis. Et ideo id quod naturale est homini potest aliquando deficere, ST II-II, 57, 2 ad 1).
} 
ocasiones el mencionado pasaje de Aristóteles ${ }^{19}$. El primero de sus comentarios, titulado Super Ethica commentum et quaestiones, es el más importante y extenso y contiene, además de la paráfrasis del texto aristotélico, una serie de dubia o quaestiones sobre cada fracción del texto que se comenta ${ }^{20}$. En una de estas dubia, Alberto muestra cómo el problema de la variabilidad del derecho natural está íntimamente relacionado con el principio del mal menor: "Es verdad que las cosas [justas] por naturaleza en cuanto a lo que pertenece a su esencia nunca cambian, pero el uso de ellas cambia, pues a veces falta aquello que es según la naturaleza recta, y conviene hacer aquello que es según la naturaleza débil. Como sucede en la medicina, la cual a veces administra a los que están enfermos por un exceso de calor cosas que exceden en frío, las cuales absolutamente consideradas no son sanas. Así también corresponde a veces que cambien las cosas [justas] naturales a causa de diversos accidentes, a fin de que se evite un mal mayor"21.

Sin embargo, san Alberto también restringe esta posibilidad de cambio en lo que es justo por naturaleza. Para tales efectos, Alberto distingue entre aquello que, siendo justo por naturaleza, "mira a la naturaleza de un modo absoluto, y su fuerza proviene solo de ella, y no es determinado por alguna institución; como, por ejemplo, los axiomas en las cosas morales, como que no se debe hacer daño a otro, que hay que honrar a Dios y otras de esta clase. Estas no reciben dispensa alguna, pues pertenecen a la verdad de la vida, que por ningún escándalo o daño pueden dejar de cumplirse" 22 de aquello que, siendo también justo por naturaleza, "mira a la naturaleza con alguna disposición. Y así, según algunas diversas disposiciones de esta clase entre los hombres, se determinan determinados preceptos que miran ciertos especiales modos, como que una [la mujer] sea de un [hombre] y que alguien otorgue un determinado honor a sus padres. Y las [cosas justas] de esta clase en cuanto a su sustancia siempre permanecen, pero nada impide que a veces en ellas pueda haber dispensa, para que se evite un inconveniente mayor"23.

\footnotetext{
19 Poblete (2020) p. 223; 237.

${ }^{20}$ La influencia de este comentario sobre el de santo Tomás es sustancial Dolg (2001) p. 25, y no puede ser más directa. El comentario de Alberto corresponde a una compilación de clases y disputas públicas llevada a cabo entre 1250-52 Cunningham (2008) p. 38. y santo Tomás, alumno de Alberto en ese entonces, parece haber sido el compilador a cargo Hoffmann, Müller, y Perkams (2013) p. 3. De este modo, el Super Ethica de Alberto puede ser considerado el más influyente -siempre mediado por el de Tomás- en la tradición ética posterior Celano (2016) p. viii.

21 SE, 359: 79-90: Verum est enim, quod naturalia quantum ad essentialia numquam variantur, sed usus eorum variatur, quia aliquando relinquitur id quod est secundum naturam rectam, et expedit facere id quod est secundum naturam infirmam, ut patet in medicina, quae aliquando dat infirmis secundum excessum caloris excedentia in frigiditate, quae simpliciter non sana sunt. Ita etiam oportet aliquando mutari ipsa naturalia propter diversa accidentia, ut evitetur maius malum.

22 SE 360: 46-53: "[Est quoddam iustum naturale, quod] respicit naturam absolute, et illud ex ea solum habet vigorem, et non ex aliqua institutione determinatum, sicut dignitates in moribus, ut non esse alicui iniuriandum, deum esse honorandum et huiusmodi; et haec nullam dispensationem recipiunt, quia pertinent ad veritatem vitae, quae pro nullo scandalo vel nocumento sunt deserenda".

23 SE 360: 53-61: "[Est aliud iustum naturale, quod] respicit naturam cum aliqua dispositione, et sic secundum aliquas diversas hominum dispositiones huiusmodi contraria sunt praecepta determinata ad speciales quosdam modos, sicut quod una unius sit et quod aliquis determinatus honor detur parentibus. Et huiusmodi secundum substantiam semper manent, sed nihil prohibet quandoque in talibus dispensari, ut evitetur maius inconveniens".
} 
La acotación de Alberto es interesante. Lo que da lugar al cambio de lo justo natural es la posibilidad de que haya cierto decaimiento o debilitamiento en la naturaleza. La variabilidad de la justicia natural está sujeta a un defecto en la realización concreta y material de lo natural. Para mostrar este punto, Alberto recurre al ejemplo de la medicina, tan querido del mismo Aristóteles. Una cosa excesivamente fría no es, por sí misma, sana, sino más bien dañina para la salud. Pero para quien está enfermo por exceso de calor, representa un alivio. En este caso, la proporción o desproporción del medio terapéutico no mira a la naturaleza del enfermo considerada de modo absoluto, sino a su naturaleza acompañada de cierta disposición; aquí, la enfermedad. Así pues, como señala san Alberto, existen ciertas cosas que son justas por naturaleza, pero que lo son por consideración a la naturaleza en cuanto dispuesta de determinado modo. Por tanto, si esa disposición no se encuentra o se halla de modo deficiente, puede cambiar. Asimismo, aunque la restitución de los bienes dados en depósito es algo justo por naturaleza, si el depositante está mal dispuesto (v.gr. enloquecido, en un acceso de ira, etc.), cesa la obligación mientras no cese la indisposición del depositario, y quede restablecido el orden natural de las cosas (viz. su salud mental). En cambio, hay otras cosas justas por naturaleza que no están sujetas a cambio, pues miran a la naturaleza sin tomar en consideración ninguna disposición suya. En otras palabras, miran a la naturaleza de modo absoluto. Así, por ejemplo, el precepto de derecho natural que prohíbe el homicidio es absoluto, y no admite excepción, pues no mira a la naturaleza del hombre en cuanto tenga o no cierta disposición (es decir, no importa si el sujeto es bello o feo, si está sano, enfermo, loco o cuerdo; ni siquiera si es bueno o malo). Si el sujeto es inocente-que en este contexto se entiende como que no amenaza con llevar a cabo una agresión actual o inminente contra la vida de otro- nunca es lícito intentar directamente su muerte.

En síntesis, los elementos que integran la recepción medieval del texto aristotélico serían los siguientes. Primero, debe existir algo debido, algo justo, por naturaleza. Es decir, el fundamento de dicha obligación se encuentra en la naturaleza humana. Segundo, lo justo natural es algo que obliga ut in pluribus, es decir, en la mayoría de los casos. Tercero, producto de una circunstancia extraordinaria, esta obligación puede dejar de ser exigible. Esto es algo excepcional o ut in paucioribus, y que mantiene su vigor en la medida en que la circunstancia extraordinaria se mantenga. Cuarto, lo que obliga a omitir el cumplimiento de la obligación es el daño de su observancia. Quinto, en esas circunstancias, se debe aplicar el principio del mal menor, es decir, optar por el curso de acción menos malo. Sexto, del conjunto de cosas justas por naturaleza, solo están sujetas a cambio aquellas que miran a la naturaleza con cierta disposición, y no aquellas que miran a la naturaleza absolutamente considerada.

\section{LA RETENCIÓN DE LAS INDIAS Y LA VARIACIÓN DE LO JUSTO NATURAL}

Como veremos a continuación, existe una significativa correspondencia entre esta bien asentada doctrina y los argumentos esgrimidos en las contiendas indianas en torno a la retención de las tierras conquistadas. Para mostrar este punto, fijaremos nuestra atención en tres autores significativos en la disputa, y que acudieron a la antedicha doctrina para de- 
fender la retención de las Indias por parte de la Corona: el dominico Francisco de Vitoria, el licenciado Francisco Falcón, y el jurista Juan Solórzano de Pereira. Este grupo de autores puede, además, dividirse en dos categorías conforme a los bienes que, en su concepto, justificarían la retención. En efecto, mientras Vitoria y Falcón se amparan en el imperioso resguardo de la fe de los Indios, Solórzano agrega en su argumentación razones meramente políticas y de bien común. Nuestra exposición, pues, se ajustará también a esta división.

\section{Retener por un bien SObRenatural: Vitoria, Falcón y la Fe de los indios}

Francisco de Vitoria dedicó su Relectio de Indiis principalmente a la determinación de los títulos justos para adquirir el señorío de las Indias, y a la exclusión de los injustos. En realidad, por razones principalmente coyunturales, el teólogo parece aproximarse al problema de la adquisición y de la retención con cierta indistinción. En efecto, la reducida distancia temporal entre la Relectio y el descubrimiento de América (menos de 50 años), volvía prácticamente equivalentes la determinación de la justicia o injusticia del dominio sobre las Indias, por una parte, y la cuestión sobre si debían restituirse o no, por otra. Así, aunque, como veremos, Vitoria no deja de tocar el tema de la justicia de la retención de las Indias, sus observaciones son más bien tangenciales y como breves digresiones respecto de otros objetivos, a su juicio más apremiantes.

En todo caso, escapa a todo cuestionamiento la importancia que le atribuye Vitoria a la aclaración de los justos títulos para adquirir y dominar sobre las tierras de ultramar pues, si la conquista llegase a ser considerada ilegítima, simplemente correspondería prima facie retirarse del Nuevo Mundo. Se trata de una sentencia común entre los autores iusnaturalistas. La adquisición de una cosa por medios ilegítimos entraña la obligación de restituir: ille qui abstulit tenetur restituere (ST II-II, q. 62, a. 6, sc.). Y esto, como señala santo Tomás, vale también para los reyes que arrebatan bienes a otras personas con violencia e injustamente: "Aquellos que, contra la justicia, sustrajesen las cosas de otros haciendo uso del poder público, obran ilícitamente, cometen rapiña, y están obligados a restituir"24.

Vitoria, por supuesto, no considera que los Reyes de España se encuentren en el caso aquí descrito. De hecho, la Relectio enumera y justifica una serie de títulos justos -luego de haber enumerado y desechado otra serie de pseudo-títulos, carentes de toda justicia- por los que la Corona pudo legítimamente entrar a dominar las Indias. Sin embargo, el teólogo de Salamanca explica que habría cierto título que podría amparar la retención de esas tierras, incluso si hubiesen sido conquistadas por medios ilegítimos: “[...] Es evidente que después de que se han convertido allí muchos bárbaros, no sería conveniente ni sería lícito al Rey abandonar por completo la administración y el gobierno de aquellos territorios" 25 .

Vitoria se coloca en un supuesto extremo. Si por cualquier motivo todos los títulos que ofrece fallasen en cuanto a su justicia, la adquisición de las tierras habría sido injusta y, por tanto, correspondería por derecho natural restituirlas a los nativos. Sin embargo, la

\footnotetext{
${ }_{24}$ ST II-II, q. 66, a. 8, c.: Si vero contra iustitiam aliqui per publicam potestatem violenter abstulerint res aliorum, illicite agunt et rapinam committunt, et ad restitutionem tenentur.

25 RDI I, 3, 17: [...] patet quod iam, postquam ibi facta est conversio multorum barbarorum, nec expediret nec liceret principi omnino dimittere administrationem illarum provinciarum.
} 
circunstancia de que un número significativo de indios se hayan convertido al cristianismo parece alterar el escenario. En efecto, el Rey no podría abandonar la administración y gobierno de las Indias pues, con toda probabilidad, los indios perderían su fe y, de acuerdo con la cosmovisión de Vitoria, retornarían a la idolatría. La posibilidad de que se produzca este 'daño' (damnum) en la fe de los indígenas, cuyo resguardo ciertamente cae bajo los deberes de una monarquía católica como la de Castilla y León, altera la obligación natural de restituir; al menos, mientras esta posibilidad sea fundada.

La situación descrita cumple con todos los elementos que, según los primeros comentadores de Aristóteles, deben concurrir para que cambie lo justo natural. En efecto, si se trata de tierras adquiridas injustamente, existiría por derecho natural la obligación de restituirlas. Sin embargo, concurre en el caso una circunstancia extraordinaria que altera la justicia de la situación: el poco arraigo de la fe de los indios, y el previsible perjuicio para ella como consecuencia del desamparo español. Ahora bien, dado que la obligación natural de restituir lo injustamente ocupado es una de aquellas sujeta a ponderación de bienes y males, la respuesta resulta clara. La fe es un bien espiritual y de orden sobrenatural, mientras que la propiedad sobre las tierras, un bien de orden puramente temporal. Por lo mismo, para Vitoria no se trata simplemente de justificar la retención de las Indias si ese fuese el deseo de los Reyes, sino que, según este razonamiento, la Corona estaría absolutamente obligada a conservar la administración de las Indias mientras no cese el temor de que los indios pierdan la fe. El abandono sería simplemente ilícito.

Vale la pena notar que, al igual que en el caso del depósito, también aquí la variación de lo justo natural se ve posibilitada por una débil condición de la naturaleza. Usando los términos en que se expresa san Alberto Magno, la obligación de restituir no es de aquellas que miran a la naturaleza absolutamente considerada, sino a la naturaleza acompañada de cierta disposición (naturam cum aliqua dispositione). En este caso, la disposición referida es la condición actual de la fe de los indios que, en el razonamiento de Vitoria, es considerada como débil: no está todavía suficientemente asimilada, continúa mezclada de elementos paganos, etc. Así, tal como un arma depositada no debe ser restituida a un dueño que la reclama en estado de demencia, tampoco ha de restituirse a los nativos neófitos la administración de sus reinos, incluso si hubiesen sido adquiridos por medios ilegítimos, a causa del grave peligro que amenaza su fe. Lo contrario equivaldría a provocar un daño mayor que aquel que la restitución pretende reparar.

Es verdad que, si se toma en cuenta la Relectio en su totalidad, podría dar la impresión de que este pequeño pasaje no es más que un apéndice sin importancia. Pero, a pesar de su breve extensión, el maestro de Salamanca tuvo este argumento en la más alta consideración. De hecho, no fue sino este razonamiento el que esgrimió frente a Carlos $\mathrm{V}$ para convencerlo de no retirarse de las Indias cuando, aquejado por graves problemas de conciencia sobre los títulos para conquistar y permanecer en el Nuevo Orbe, pensó seriamente en ordenar el abandono ${ }^{26}$. Además, la Relectio tomada en su totalidad da cuenta de

26 Cf. Pérez Amador Adam (2011) pp. 124 y 139 nt. 13; Hanke (1949) pp. 115-117; Carlos V, "Provisión que manda sobreseer todas las conquistas y descubrimientos que estaban cometidas y mandadas hacer en las provincias del Perú hasta el día de la notificación de la provisión 16 de abril de 1550”, p. 255. 
la radicalidad de la posición del dominico: si la justicia de los títulos fallase, y no existiese real peligro de la fe de los nativos, no existiría razón alguna para que la Corona permaneciese en América. El mismo Vitoria se encarga de aclarar que, en su concepto, los factores de carácter temporal -digamos, político-económicos- no tienen fuerza suficiente para excusar la restitución ${ }^{27}$. Para el teólogo, la restitución de la soberanía a los naturales no traería necesariamente consigo un cese del comercio, pues los indios abundan en muchos bienes que los españoles podrían adquirir por justo intercambio. Además, continúa, muchas cosas en las Indias no se hallaban bajo dominio de dueño alguno, las cuales serían, por tanto, comunes a todos lo que quieran utilizarlas (incluidos los españoles). Finalmente, tampoco es verdad que quedarían afectadas gravemente las arcas reales. En efecto, desde el punto de vista de la justicia no habría inconveniente en gravar con impuestos el oro y la plata procedentes de las Indias, pues la navegación en estos mares se realiza bajo la protección de los reyes españoles ${ }^{28}$. En suma, para Vitoria es claro que las alegaciones de tipo político-económico no son capaces de modificar la eventual necesidad de restituir. Había que dar con otra razón, de carácter moral. Esa sería para el dominico la conservación de la fe cristiana, no hace mucho recibida y todavía frágil. Un argumento semejante sí sería procedente para determinar la justa retención de las Indias y el señorío de la Corona sobre los naturales ${ }^{29}$.

Muchos elementos diferencian a Francisco Vitoria del famoso procurador de indios, el licenciado Francisco Falcón. Mientras el primero es teólogo, el otro es abogado. Aquel vive en España, este, en cambio, en Indias. Mientras uno es un pensador que escribe en los albores del descubrimiento y conquista de América, el otro es un hombre práctico que lo hace en un despacho situado en una ciudad virreinal, Lima, bien asentada en territorio de ultramar. Es verdad, en mucho difieren estas figuras; $y$, sin embargo, coinciden en un punto fundamental: que los reyes están moralmente impedidos de abandonar las Indias ${ }^{30}$.

El único trabajo de Falcón que ha llegado hasta nosotros es su Representación en defensa de los indios de 1567 dirigida a una audiencia eclesiástica, el Segundo Concilio Limense $^{31}$. Se trata de un texto que, según ha mostrado Lohmann, tuvo influencia en los obispos, como se puede apreciar en diversas disposiciones conciliares ${ }^{32}$.

En su Representación, el licenciado argumenta que los únicos títulos que podría invocar la Corona de Castilla en justificación de la conquista serían la guerra justa y la donación papal. El primero de ellos, explica, resulta improcedente ya que no habría existido motivo real para dar guerra a los indios. Y en cuanto a la donación papal por parte de Alejandro VI, señala que el único señorío que pudo haber concedido el Papa se limita a la predicación del Evangelio, sin que por ello hubiesen perdido los indios el señorío que legí-

\footnotetext{
${ }^{27} R D I$ I, 3, 17.

$28 R D I$ I, 3, 17.

29 RDI I, 3, 17.

30 A pesar de que el escrito que se conserva de FALCÓn tiene por objeto primordial la defensa de los indios, es muy probable que haya participado en la polémica sobre la licitud del derecho de conquista: LoHMANN VILLENA (1970) p. 143. Su trabajo, en todo caso, es claramente deudor del magisterio de Vitoria, de Domingo de Soto y de Bartolomé de las Casas: lohmann Villena (1970) p. 133.

31 Lohmann Villena (1970) p. 154. Para las actas del Concilio: Vargas Ugarte (1949) I: 95-257.

32 Lohmann Villena (1970) p. 159.
} 
timamente ejercían sobre lo suyo. En esto Falcón sigue muy de cerca a fray Bartolomé de Las Casas $^{33}$. Por consiguiente, en ausencia de justo título, la ocupación española carecería de toda justicia, y los reyes estarían obligados a restituir. Esto sería así, aclara Falcón, solo en la medida en que los indios fuesen capaces de gobernarse "justa y cristianamente" ${ }^{4}$. El licenciado asegura expresamente que esta es la intención de Carlos V, quien habría estado dispuesto a realizar esa restitución de concurrir las circunstancias correspondientes. Con todo, continúa el jurista, "justa y cristianamente le fue respondido que no le era lícito dejarlos a cuyos eran, por los grandes daños que a los mismos señores y súbditos se les seguirían de ello, tornándose a su infidelidad, y la ofensa que se hiciera a Dios nuestro Señor e injuria a la religión cristiana" 35 .

Como vemos, el licenciado Falcón conoce y sanciona la opinión de Vitoria, que para entonces era ya lugar común entre los autores de la época. En síntesis, asegura que, aunque la conquista hubiese sido injusta, y los reyes estuviesen bajo una obligación natural general de restituir, no deberían hacerlo "en este caso particular", porque el abandono español produciría graves daños a los mismos reyes y a los indios, quienes se tornarían a la infidelidad con grave ofensa a Dios.

Lo dicho muestra que la argumentación del licenciado Falcón discurre sobre la base de la antedicha doctrina aristotélica, asumida en el medioevo, según la cual lo que es justo por naturaleza está sujeto a cambio. Testimonio inequívoco de ello es la ocurrencia expresa del ejemplo clásico del depósito invocado por santo Tomás, y que Falcón coloca en directa relación con esta disputa: "como si el que hubiese tomado una espada la quisiese restituirla a cuyo era, y le hallase loco y que no podía aprovechar de ella, antes matarse, haría mal en restituirla" 36 .

Como vemos, Falcón asimila el caso del depositante, es decir, de aquel a quien se le debe la restitución de un bien, al de los indios, injustamente despojados de sus tierras y bienes, a quienes también se les debería por tanto la restitución de lo suyo. Según el relato del jurista, es claro que el defecto en la disposición natural del loco equivale a la condición incipiente y poco instruida de la fe de los indios. A cincuenta años de la Relectio, el daño para la fe de los indios todavía es invocado para justificar la permanencia española en el Nuevo Mundo; y a casi trescientos años de que santo Tomás se hiciera cargo del pasaje aristotélico sobre lo justo natural, el ejemplo del depósito sigue resolviendo conflictos de variabilidad del derecho natural.

\section{Retener por un bien temporal: el giro de Juan de Solórzano ante la RETENCIÓN DE LAS INDIAS}

La doctrina del cambio de lo justo natural también parece haber sido conocida por Juan de Solórzano Pereira, considerado el jurista más importante del siglo XVII ${ }^{37}$. Su argu-

\footnotetext{
33 Lohmann Villena (1970) p. 133.

34 FALCÓN (2017) p. 137.

35 FALCÓN (2017) p. 137. Se modernizó la ortografía.

36 FALCón (2017) p. 137.

37 Cf. García Hernán (2007) pass.; Barrero García (1989) pp. 65-85.
} 
mentación en esta materia, aunque en parte importante sigue a la del teólogo de san Esteban y la del licenciado Falcón, no deja de distanciarse de ella en algunos puntos significativos.

Más aún que en el caso de Falcón, Solórzano entra a la discusión sobre la retención de las Indios ante una presencia española en ultramar mucho más consolidada que cuando escribía Vitoria. Por lo mismo, lo que para el profesor salmanticense no mereció más que una observación tangencial, para Solórzano resultó ser un asunto capital.

Su trabajo De indiarum iure fue publicado en $1629^{38}$, es decir, 90 años después de la Relectio de Vitoria y 130 años después de la llegada de Colón al Nuevo Mundo ${ }^{39}$. Por lo mismo, se halla ante una realidad político-religiosa bien distinta. La fe cristiana de los naturales daba cada vez mayores muestras de arraigo ${ }^{40}$. Además, la presencia española era más extendida, con la consiguiente dependencia económica de la Corona respecto de las Indias, una dependencia que, como explica Solórzano, también mantenían los mismos indios con respecto a la Corona. Estos factores tuvieron una doble consecuencia. Por una parte, causaron que la pregunta por la justicia de la adquisición de las Indias comenzara a distanciarse de la cuestión de su justa retención. Más aún, respecto de esta última cuestión, llevaron a que el jurista operara un giro con respecto a sus predecesores: la averiguación sobre la retención de las Indias trascendía ya el ámbito de la sola conservación de la fe, y debía vincularse más sustantivamente con la mantención del orden político imperial en su totalidad.

No es de extrañar, pues, que de los tres libros que componen su tratado, Solórzano dedique un libro completo solo a la discusión de los títulos que justificarían la retención de los reinos adquiridos (a diferencia del caso de Vitoria que, como vimos, no pasaba de una acotación marginal, sin perjuicio de su importancia práctica). Y entre todos los títulos invocados para justificar la retención de las Indias, el último de ellos, considerado por él como "el más eficaz", se funda en la imposibilidad práctica de restituir ${ }^{41}$. En efecto, se trata de un título que "proviene de la dificultad, por no decir imposibilidad de la restitución,

\footnotetext{
38 Sobre la difícil composición de esta obra, a lo largo de diez años: García Hernán (2007) pp. 157-160.

39 Existe una cuidada edición bilingüe de la obra: Solórzano Pereira, DII; De Indiarum iure. Liber 2 [1]; Solórzano Pereira, De Indiarum iure. Liber 2 [2]; Solórzano Pereira, De Indiarum iure. Liber III.

40 Cf. de la Hera (1996) p. 91.

${ }^{41}$ Los otros títulos que, según SolórZano, justificarían la retención de las Indias testimonian claramente su oficio y talante jurídicos. Así, asegura de entrada que el carácter tan extendido de la discusión sobre los justos títulos para adquirir las tierras conquistadas constituye ya un indicio de que es lícito retener dichas tierras (DII III, 1: 1-2), pues la primera cuestión es más difícil de justificar que la segunda. Esto, explica SolórZANO, sucede por muchas razones entre ellas, que "en la duda y casos análogos se prefiere a quien tiene la condición de poseedor" (DII III, 1: 12) y porque, de acuerdo con BALDO, "la posesión subsiguiente es interpretativa de los títulos" (DII III, 1: 24; PI I, XI, 20). Asimismo, como criterio general, establece que, dado que los monarcas españoles consultaron tantos pareceres a propósito de la conquista y recibieron la aprobación de un número tan elevado de hombres instruidos y prudentes, no tiene sentido seguir disputando sobre los justos títulos de adquisición (cf. PI, I, IX 2; DII, III, 2, 1), porque aun en el supuesto de que no existieran, su buena fe mantenida de manera constante, sumada al paso del tiempo, indica que ya ha operado la prescripción (DII III, 2: 40-44; PI I, XI, 15 y 19). En la misma línea, en su Política Indiana explica que "esto procede mucho más llanamente cuando se trata no ya de adquirir, sino de retener lo adquirido, en que siempre todas las leyes admiten mayor latitud, y en causas que aun en sí pueden recibir dudas, y variedad de opiniones requieren que se siga la que favorece a la posesión” (PI I, I, 20).
} 
habiendo sido convertidos ya los indios a la fe, y encontrándose entramados entre sí por nexos mutuos los asuntos de los españoles y de los indios" ${ }^{\prime 2}$.

Solórzano introduce este título asegurando que su validez se sostiene incluso si todos los anteriores fallasen. De ahí que este argumento ocupe un lugar eminente en su razonamiento y sea, de hecho, el más extenso. Así, al igual que Vitoria, el jurista asegura que su argumento tiene valor incluso si la adquisición de las Indias hubiese sido ilegítima y que, por tanto, por derecho natural debiesen ser restituidas. El jurista comienza haciendo referencia a la situación política que existía entonces entre España y las Indias: "Se puede considerar que, aunque todos los títulos anteriores fallasen, hoy en día, como dijimos antes, con el correr del tiempo, la religión y la república de indios y españoles habría comenzado a ser una, y a constituirse bajo la tuición y gobierno de nuestro mismo Rey español. Y la condición, fuerzas y nervios de uno y otro reino se encontrarían tan entrelazados e imbricados, que no se podría separar uno del otro sin un gran y evidente peligro y perjuicio de ambos" ${ }^{33-44}$.

Aquí Solórzano presenta en un solo lugar dos supuestos que determinan, respectivamente, dos argumentos distintos. La unión o dependencia mutua entre españoles e indios se da, como observa el jurista, en dos niveles: la religión y la república. Más aún, la intensidad de esta relación de mutua dependencia sería tal que intentar una separación entre ambos resultaría en un peligro y perjuicio, de los indios no menos que de los españoles, "grande y evidente" 45 .

Ahora, los bienes que componen esta unidad doble (viz. la religión y la sociedad civil) son de tal modo dispares, que Solórzano los trata expresamente aparte. Y así, con respecto al problema de la religión, el argumento de Solórzano es prácticamente idéntico al de Vitoria: "En confirmación de esta opinión [...] se puede tener en cuenta, en primer lugar, la índole de los indios mismos, su ligereza e impericia, que no permite en modo alguno que

42 DII III, 5: qui ex difficultate aut verius impossibilitate restituionis descendit, indis iam ad fidem conversis et eorum et hispanorum rebus mutuis inter se nexibus complicatis.

43 DII III 5, 25-27: Considerari potest quod, quamvis praedicta omnia deficerent, cum tamen hodie, ut supra tetigimus, tempore lapsu hispanorum et indorum religio et respublica una esse coeperit et sub eiusdem hispani nostri regis tuitione et gubernatione constitui atque utriusque regni status, vires et nervi ita commixti et complicati sint, ut alterum ab altero sine magno et evidente amborum periculo et dispendio separari non possit.

44 La misma idea se expondrá, años más tardes, en Política Indiana (I, XI, 23), donde se señala que incluso LAS CASAS es de este parecer.

45 Es notable cuan de cerca sigue SOlÓRZANO a ViTORIA incluso en la forma de presentar su argumento. Al igual que el dominico, SolórzANo asegura que su argumento mantiene vigor, "aunque todos los títulos anteriores fallasen”, es decir, aunque la adquisición de las Indias no hubiese estado amparada por título justo alguno (lo cual, entrañaría la obligación natural de restituir). Y más adelante, SolóRZANo también recuerda que, de ser verdadero su argumento, la cuestión abandonaría el terreno de la mera justificación, para entrar de lleno en el de la obligación. En efecto, el jurista afirma que los reyes están obligados a conservar las Indias, “y lo que es más grave: no podrían dejarlas ni abandonarlas sin cometer pecado grave” (DII III, 5, 1-2). Esta coincidencia no solo pondría en evidencia el dato anecdótico de que Solórzano haya leído los escritos de Vitoria (lo cual es bastante obvio). Mucho más significativo todavía es que, por la naturaleza de los juicios en que coinciden, esto muestra que ambos están aplicando en todo su sentido y alcance la doctrina aristotélica y tomista del cambio de lo justo natural: la obligación natural ha cambiado, de modo que resulta irracional, por el momento, restituir las tierras (incluso las adquiridas injustamente). 
se les deje a su propia potestad y gobierno, sobre todo después de haber dado su nombre a la religión cristiana" ${ }^{46}$.

De hecho, hace suya la opinión de otros autores que estiman que "ante el hecho de la barbarie y ceguera de estos indios, podría ocurrir fácilmente que, desaparecidos el dominio y gobierno españoles, volvieran al pecado de apostasía y a sus originarias costumbres idolátricas, si se les dejase en poder de sus antiguos señores y reyezuelos (regulis)" ${ }^{47}$.

El razonamiento de Solórzano refleja nítidamente la visión vitoriana en torno a la obligación de restituir. Por derecho natural, deberían restituirse las tierras adquiridas injustamente. Pero la Corona está impedida de hacerlo en este caso particular, por un defecto en la condición natural (viz. la "índole misma de los indios", esto es, su "barbarie y ceguera"). Así, de la observancia de la obligación de restituir se seguiría un daño mayor que de retenerlos y, por tanto, sería irracional, pues si se los abandona a su gobierno, "podría ocurrir fácilmente" que apostaten de la fe y retornen a la idolatría. De hecho, el mismo Solórzano explicita la ponderación de la entidad de los bienes en juego, dando aplicación al principio del mal menor: "Los bienes de orden inferior no se deben restituir con perjuicio y detrimento notable de los bienes (incluso temporales) de orden superior, [...]. De donde, mucho más se prueba esto mismo allí donde amenazan el perjuicio y el peligro de los bienes espirituales, esto es, de la religión, cuya consideración debe ser suma" ${ }^{48}$.

Al igual que en el caso de Vitoria, la consideración del bien de la religión se inserta y encuentra su relevancia al interior de un argumento mayor de naturaleza filosófica. Aquí la premisa determinante dice relación con el perjuicio de bienes superiores frente a la obtención de otros inferiores. Puesto que el bien de la religión es un bien espiritual (o sobrenatural) y, por tanto, superior a todo otro bien temporal (o natural), la cuestión de la justa restitución de los reinos (bien temporal) cede ante la amenaza de la fe (bien espiritual). En suma, la situación actual es tal que no puede observarse lo que es justo 'en la mayoría de los casos' (ut in pluribus); en otras palabras: lo justo natural ha cambiado ${ }^{49}$.

46 DII III, 5, 4-6: Pro cuius sententiae confirmatione [...] primum ipsorum indorum natura, facilitas et imperitia considerari potest, quae nullo modo permittit, ut suae potestati et gubernationi reliquantur, maxime postquam christianae religioni nomen dederunt.

47 DII III, 5, 7-8: Supposita eorundem indorum barbarie et coecitate, facile contingere posset, ut amoto hispanorum imperio et gubernatione, si sub antiquis dominis et regulis relinquerentur, in apostasiae crimen et pristinae idolatriae consuetudinem recidivarent.

48 DII III, 5, 36-37: Nam bona inferiors ordinis restituenda non sunt cum iactura et detrimento notabili bonorum etiam temporalium superioris ordinis, [...]. Unde multo magis idem probandum est, ubi imminet iactura et periculum bonorum spiritualium, religionis scilicet, cuius consideratio summa esse debet.

${ }^{49}$ Más adelante, en su Política Indiana insiste en que proceder de otra manera significaría "faltar a lo prometido a la Iglesia, al amparo de los indios ya convertidos que sin su cuidado apostatarían y volverían a su idolatría y perversas costumbres, y resultarían otros muchos y muy graves inconvenientes [...]" (PI I, I, 22). El pasaje es interesante pues, como veíamos más arriba, del abandono de los indios no solo podría seguirse un perjuicio para la fe, sino también "otros muchos y muy graves inconvenientes", a saber, daños de orden temporal, tanto para indios como para españoles.

A propósito de este argumento, podría plantearse una objeción al modo en que la hemos contextualizado aquí. En efecto, hemos mencionado que, para el tiempo en que SOlÓRZANO escribe, puede constatarse una evolución sustancial en lo que al arraigo de la fe de los indios se refiere. ¿Cómo es, pues, que SolóRZANo sigue invocando la fragilidad de la fe de los nativos para justificar la permanencia de los españoles en América? Probablemente la respuesta a esta cuestión es doble. Por una parte, hay que distinguir entre un arraigo extensivo y uno insensivo. 
La superioridad del bien de la religión sobre bienes de naturaleza temporal es simplemente evidente para Solórzano y los autores de la época. Pero en el pasaje que comentamos, y antes de entrar al problema de la religión, Solórzano afirma que "los bienes de orden inferior no se deben restituir con perjuicio y detrimento notable de los bienes (incluso temporales) de orden superior". A diferencia de Vitoria, Juan de Solórzano admite expresamente la posibilidad de que una ponderación entre bienes de un mismo orden (v.gr. temporales), lo que, dicho en terminología aristotélica, puede determinar un cambio en lo justo natural ${ }^{50}$.

Es por esta razón que Solórzano también se hace cargo del problema, ahora estrictamente político, de ponderar los bienes públicos que estarían en juego en una posible restitución de la Indias. En este punto, el jurista toma distancia de Vitoria, y es lógico que lo haga. Hemos visto ya que, para el teólogo de Salamanca, los posibles daños políticos y económicos que traería consigo el abandono de las Indias, o bien no existirían, o bien, de existir, no serían de entidad suficiente como para suspender la obligación de restituir ${ }^{51}$. En las circunstancias actuales, en cambio, Solórzano estima que el perjuicio que se seguiría para ambos, indios y españoles, si se restituyen las Indias, sería grave y justificaría una prudente dilación en la restitución. Así lo expone, invocando una serie de autoridades a fin de evidenciar el consenso generalizado que existía en este punto entre los pensadores de la época. Una de ellas es fray Juan Márquez ${ }^{52}$, quien "resuelve que la restitución de las cosas ajenas no debe hacerse cuando de ella se seguirían gravísimos daños públicos; y, por lo tanto, no se ha de condenar fácilmente a los reyes que tienen cosas ajenas, incluso conscientes de que no son suyas, si solo conocieran que, probablemente, su restitución traería consigo gravísimos perjuicios a sus reinos" ${ }^{53}$.

Claramente, aquí ya no se habla de bienes absolutamente diversos o pertenecientes a órdenes esencialmente dispares. A pesar de sus diferencias, lo que está en juego es, por una parte, unos gravísimos daños públicos y, por otra, la restitución de la soberanía a los indios. En ambos casos, pues, se trata de bienes públicos o civiles. Por lo demás, y al menos según la versión de Solórzano que apuntábamos más arriba, este daño afectaría no solo a los españoles, sino también a los indios. Nuevamente aquí se está ante un caso semejante al ya

Puede ser que, para los tiempos en que escribe SolórZano, la fe haya cundido extensivamente en las Indias, es decir, alcanzado a una mayoría sustantiva de los indios. Con todo, puede perfectamente ser el caso de que, para entonces, la instrucción todavía mantuviese rasgos primitivos, y mezclados con motivos religiosos paganos. Pero, además, a diferencia de un teólogo como Vitoria, Solórzano es un abogado comisionado por la monarquía española, para defenderla de las acusaciones que le hacían sus adversarios protestantes (Grocio, por ejemplo, cf. PI I, IX, 2), que desacreditaban a su patria y pretendían impugnar los títulos que justificaban su permanencia en América García Hernán (2007) p. 157; 164. Por lo mismo, Solórzano no dejó de lado ningún argumento que pudiese apoyar su causa, dándoles el mayor alcance posible y minimizando toda restricción de ellos.

50 DII III, 5, 36-37.

51 RDI I, 3, 17.

52 Probablemente incorporada por Solórzano a su regreso a España el año 1627 para los últimos retoques al manuscrito: PereÑa (1994) p. 25 en relación con la expresión novissime que emplea en DII III, 5, 25-27.

53 DII III, 5, 25-27: resolvit restitutionem alienarum rerum non esse faciendam, quando per eam consequerentur maxima damna publica, ob idque non esse facile damnandos reges qui tenent aliqua aliena, etiamsi scirent non esse sua, modo probabiliter scirent eorum restitutionem consecutura gravissima suorum regnorum incommoda. 
clásico del depósito, que tiene un especial interés porque vale incluso en el supuesto de que el tenedor de la cosa la tenga en su poder de manera injusta ${ }^{54}$.

A diferencia del problema del daño a la fe, la solución de esta cuestión política no parece ser de necesidad tan rigurosa, sino que precisa la mediación de un juicio prudencial. Parte de esta inseguridad parece reflejarse en el modo en que se expresa el mismo fray Juan Márquez, quien afirma que "no se ha de condenar fácilmente a los reyes...". El rey debe ponderar el bien de su pueblo, el de los indios, y la gravedad de los daños. El supuesto entonces, tal como lo describen Solórzano y fray Márquez, es que los daños serían gravísimos, y lo serían para ambos reinos. Lo justo natural, pues, ha cambiado también en esta situación pues, como diría santo Tomás, observar la obligación de restituir sería más dañoso (damnosum) y, por tanto, irracional.

\section{UNA CRÍTICA AL ARGUMENTO DE SOLÓRZANO}

No faltan los autores que han planteado que las ideas de Solórzano acerca de la posible retención de las Indias por parte de los españoles incluso en la hipótesis de que su ocupación hubiese sido ilegítima significan, en la práctica, una negación de la doctrina clásica de la guerra justa. Dicho con otras palabras, sus ideas no serían más que una consagración del derecho del más fuerte ${ }^{55}$. En efecto, según esta crítica, las tesis solorzianas llevan a concluir que la sola existencia de un Estado permitiría purgar, pasado el tiempo, cualquier vicio referido a la legitimidad de su origen. Puesto que para el jurista indiano la costumbre es el criterio que permite interpretar la ley, la práctica del vencedor sería, en definitiva, su criterio de legitimación ${ }^{56}$. De este modo, las causales de la guerra justa solo tendrían valor en la medida en que no hubieran prescrito. Esta sería una idea que nunca plantearon ni Tomás de Aquino ni Vitoria y que significaría subordinar los criterios de justicia a los del bienestar, al cálculo de costos y beneficios, de manera que la interpretación de la ley y lo justo quedará a merced de lo que señale la situación dada ${ }^{57}$. La actitud comprensiva de Solórzano ante los abusos de la Conquista se justificaría por los bienes religiosos que ella ha traído consigo, de modo que el suyo sería un "maquiavelismo teológico", un peculiar iusnaturalismo que en la práctica implica negar los criterios de la guerra justa ${ }^{58}$. Así, mientras que en la teoría clásica de la ley natural la ley injusta no es ley en sentido propio"59, "Solórzano propone justificar la retención de América a partir de criterios y de principios que apuntan al reconocimiento de lo social dado como fundamento de la ley y de la justicia. El dominio español se concebirá como algo que de por sí constituye una realidad apta para determinar

\footnotetext{
54 Así lo señalará Solórzano, más adelante, en su Política Indiana: "aun en los reinos injustamente ocupados cesa la obligación de restituirlos cuando ya están mezclados con otros que legítimamente poseen, sin cuyo notable daño, quiebra y jactura, y la de su estado no se podrían restituir aquellos” (PI I, XI, 23).

55 Castañeda (2006) pp. 110-111.

56 CASTAÑeda (2006) pp. 114-115.

57 Cf. Castañeda (2006) pp. 120-121.

58 Castañeda (2006) pp. 122-123.

59 Sobre el alcance de esta afirmación en la tradición filosófica: Massini Correas y García-Huidobro (2006).
} 
qué deba ser lo justo, no tanto por que lo encarne, sino porque lo decide de por sí [...]. Una guerra resultará justa si es exitosa" ${ }^{60}$.

Ciertamente, cuando se atiende a algunas de sus afirmaciones, cabe pensar que Solórzano parece adherir a cierto probabilismo (PI, I, XI, 16) y, a primera vista, su interpretación de la relación entre la moralidad de fines y medios podría entenderse de modo proporcionalista (cf. PI I, XII, 24-25; DII III, 6, 92-105). Se trata de una cuestión que merece un estudio más detallado, pero, con los antecedentes que tenemos a la vista, no parece que sea posible concluir de modo inmediato que aquí estamos en presencia de una negación o alteración sustancial de la doctrina de la guerra justa.

En primer lugar, el problema que ocupa a Solórzano en este argumento no apunta a la adquisición de las nuevas tierras, que es donde tiene su lugar propio la doctrina de la guerra justa, sino el de su retención a más de un siglo de los hechos anteriores, que no es exactamente el mismo que el primero, aunque tiene vínculos con él. Al ocuparse del tema, no lo hace en el nivel de los principios, sino en el propio de su aplicación. Para decirlo en terminología tomista, su problema no tiene que ver con la ley, con los criterios generales de justicia, sino con el derecho, con "la misma cosa justa" ${ }^{61}$. No olvidemos que, hablando propiamente, "la ley no es el derecho mismo, sino cierta razón del derecho", que se relaciona con él como la idea que tiene el artista inspira la obra que realiza ${ }^{62}$. El derecho, entonces, es una obra que ha de determinarse en el aquí y el ahora de una situación concreta. Precisamente en este terreno se da el problema de la mutación de lo justo natural, que puede llevar a que una obligación positiva establecida por la ley moral natural pueda no ser exigible por un cambio de circunstancias. Situaciones como esta se producen in paucioribus ${ }^{63}$, y no implican una negación del principio general. Naturalmente cabe discutir si efectivamente los hechos son tales que, de producirse la restitución a que la Corona estaría obligada en principio en caso de que la conquista hubiese sido injusta, se daría lugar a los graves daños aludidos por Solórzano; pero no cabe afirmar que la solución propuesta por el jurista signifique, de por sí, una validación de cualquier orden de cosas establecido. De hecho, uno de los argumentos que emplea Solórzano para justificar la conquista tiene que ver precisamente con ciertas injusticias vigentes en las nuevas tierras que hacían que los señoríos allí vigentes fuesen ilegítimos ${ }^{64}$.

Por otra parte, la invocación de Solórzano a la prescripción no es un simple argumento ad hoc, sino que tiene raíces romanas, en el campo del derecho privado. La novedad aquí estaría, según señala Ziegler, en que aplica esta institución al derecho internacional (ius gentium). En todo caso, este es un punto metodológico que tienen en común con el propio Hugo Grocio, su adversario en estas contiendas doctrinales, quien "como es sabido,

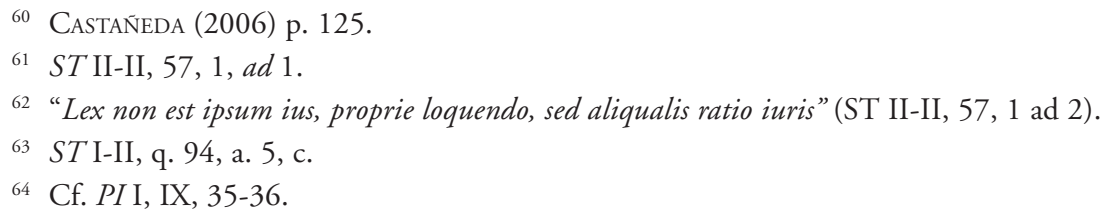


también interpretó numerosos principios jurídicos romanos como una reformulación concreta del derecho natural y el derecho internacional" ${ }^{65-66}$.

Finalmente, hay que tener en cuenta que Solórzano, lo mismo que antes de él Vitoria y Falcón, no se apoyan solo en la prescripción, sino que el argumento del que hemos dado cuenta en este texto supone el cumplimiento de ciertas condiciones de hecho que no necesariamente se dan en todos los casos, de manera que no puede decir que el autor de la Política Indiana haya mantenido una interpretación tal de la guerra justa que, en la práctica, haya significado su radical negación.

\section{CONCLUSIONES}

La cuestión de la retención de las Indias es distinta de la cuestión de la adquisición. Por circunstancias históricas, en Vitoria aparecen indistintamente tratadas, casi como equivalentes; con el tiempo, sin embargo, los problemas comienzan a distinguirse. En su Relectio de Indis, dictada en 1539, Francisco de Vitoria reduce el asunto de la conservación de las Indias a una mera cuestión de resguardo de la fe. En cuanto a los posibles perjuicios que se seguirían para la Corona, siempre político-económicos, estos no serían de suficiente entidad como para excusar la retención del dominio (en el caso hipotético de que se haya adquirido injustamente). El licenciado Falcón trata la cuestión en la misma línea que el maestro salmantino. En cambio, en Solórzano aparecen razones políticas y económicas que harían posible la retención aún en el hipotético caso en que la conquista hubiese sido injusta. Esto significa que, a lo largo de la discusión, este argumento evoluciona y adquiere un cariz más secular. En un comienzo, a pesar de tratarse formal y propiamente tal de un problema y de una argumentación filosófica (el cambio sobre lo justo natural), era, no obstante, materialmente un problema religioso (la débil fe de los indios). Posteriormente, sin que este problema religioso escapase de la atención de Solórzano, se adiciona una nueva clase de argumentación, compartida por otros autores de la época, y según la cual el problema puede exponerse pura y llanamente en términos filosóficos, pues el problema de la mutua imbricación de las sociedades no tiene un carácter teológico.

La argumentación que ofrecen los autores para justificar la retención de las Indias con independencia de su justa/injusta adquisición, no constituye un simple razonamiento creado para la ocasión, sino que descansa sobre la doctrina aristotélica del carácter variable del derecho natural, que fue ampliamente recogida por sus intérpretes medievales y, por esa vía, llegó a Salamanca.

Como hemos apuntado antes, parte de la diferencia entre Vitoria y Solórzano proviene del diverso contexto histórico en que escribe uno y otro. Vitoria escribía más de 90 años antes y ante una situación política muy diversa. La conquista aún no se consolidaba, ni social ni económicamente. Incluso si los reyes hubiesen estado obligados a la restitución, esta no provocaría un daño significativo para los españoles desde un punto de vista político-económico (más allá del que pudiera provenirles de la justa restitución de lo ajeno,

65 Ziegler (1997) p. 592.

${ }_{66}$ Para el amplio empleo que hace Solórzano de las fuentes romanas: Cuena Boy (2010) pp. 103-124. 
la cual, por ser justa, no equivale a daño en sentido propio). Además, en los años en que la Relectio salía a la luz, la mayoría de los indios seguía reconociendo como legítimos a sus antiguos reyes, despojados ahora de sus reinos por los españoles, y con la restitución se verían liberados del yugo extranjero. No podría decirse que las ideas de Vitoria se deban simplemente a una falta de conocimiento presencial. En efecto, el propio obispo de Chiapa, Bartolomé de las Casas, escribiendo pocos años después y con una experiencia de más de cincuenta años en las Indias, también sostiene que los reinos deben ser restituidos, en el sentido de que vuelvan a sus legítimos señoríos. Más aún, le recomienda en numerosas ocasiones al Rey que no haga caso de quienes afirman que los daños serían gravísimos, pues sería contrario a la verdad ${ }^{67}$.

En cambio, la situación política del imperio es tal para los tiempos del De Indiarum iure, que la dependencia entre ambas culturas se ha vuelto sustancialmente significativa. Solórzano escribe contemplando esta situación presencialmente: ambas repúblicas son una, bajo la tuición del Rey de España. La gravedad de los daños públicos proviene del hecho de que el desenvolvimiento político de los indios es ya totalmente dependiente de la institucionalidad española. Esto mismo explicaría que el argumento sobre la religión sea, en el caso de Solórzano, mucho más breve que la extensa sección que le dedica a la cuestión político-económica involucrada. La argumentación de Solórzano, un humanista dotado de una amplísima cultura, que solo en el libro III cita más de quinientos autores, va mucho más que la propia de un escrito de ocasión. Él está muy lejos de ser "un tosco apologista de un sistema injusto (como conocemos en nuestro avanzado siglo XX), sino que es un jurista inteligente y un católico creyente" ${ }^{68}$. Su tarea de jurista al servicio de la Corona no lo privó de la necesaria libertad de espíritu para criticar los abusos de los españoles en Indias, lo que le valió grandes amarguras, ya que fue forzado a retirar de su Indiarum Iure algunas afirmaciones que, aunque sus críticos admitían que eran verdaderas, podían considerarse lesivas para el prestigio de la nación ${ }^{69}$. En suma, si él pensaba que las circunstancias habían cambiado de tal manera que se hacía imposible la restitución, era porque también los indios se verían perjudicados por una aplicación inconsiderada de la eventual obligación de restituir.

\section{BIBLIOGRAFÍA CITADA}

Acosta, José de, De promulgando evangelio apud barbaros sive De procuranda indorum salute, Libri sex. Editio novissima. Lugduni: sumptibus Laurentii Anisson, 1670.

Baciero, Carlos (1994): "Fundamentación filosófica de la defensa de la Corona ante Europa". En Juan de Solórzano Pereira, De Indiarum iure. Liber III: De retentione Indiarum,

\footnotetext{
${ }^{67}$ Así lo señala, por ejemplo, respecto del señorío del Inca sobre el Cuzco, usurpado por los españoles: Respuestas a las 12 dudas de Bartolomé de la Vega, 2da conclusión a la duda 11 Las CASAS, Doce dudas, 194. En todo caso, esto también reconoce los justos títulos del Rey de Espańa para gobernar las Indias en orden al bien espiritual, según la bula papal LAS CASAS, Obras completas. 10, 197-217. Por tanto, por restitución, el dominico entiende que se reconozca al Inca como soberano legítimo de sus indios, mas no el abandono total de las Indias por parte de la Corona.

68 Ziegler (1997) pp. 593-594.

69 García Hernán (2007) pp. 160-162.
} 
III:63-109. Corpus Hispanorum de pace, 2. ser., v. 1 (Madrid, Consejo Superior de Investigaciones Científicas).

Barrero García, Ana María (1989): "La literatura jurídica del Barroco europeo a través de la obra de Solórzano Pereira", Revista Chilena de Historia del Derecho, 15: pp. 65-85.

Burley, Walter, Burleus Super libros Ethicorum. Habes in hoc uolumine candidissime lector Gualtieri Burlei expositionem super decem libros Ethicorum Aristotelis: cum duplici textu: antiquo. videlicet. \& eius qui est Argyropoli: que omnia nuper recognouit frater Ambrosius Patauus theologorum minimus ex ordine fratrum diui Augustini: ... Venecia, 1521.

Carlos V. "Provisión que manda sobreseer todas las conquistas y descubrimientos que estaban cometidas y mandadas hacer en las provincias del Perú hasta el día de la notificación de la provisión [16 de abril de 1550]", En Cedulario indiano recopilado por Diego de Encinas, Libro V, editado por Diego de Encinas, 255. Madrid: En la Imprenta Real, 1596.

Castañeda, Felipe (2006): "El derecho de retención del Nuevo Mundo en Solórzano y Pereira como superación del ius ad bellum de la Conquista", en Juan de Solórzano y Pereira: Pensar la Colonia desde la Colonia, editado por Diana Bonnett y Felipe Castañeda (Bogotá, Universidad de los Andes) pp. 109-126.

Celano, Anthony J (2016): Aristotle's Ethics and Medieval Philosophy: Moral Goodness and Practical Wisdom (Cambridge, Cambridge University Press).

Cuena Boy, Francisco (2010): "El ejemplo de los romanos", Revista Chilena de Historia del Derecho 22, No 1: pp. 103-124.

Cunningham, Stanley B. (2008): Reclaiming Moral Agency: The Moral Philosophy of Albert the Great (Washington D.C., CUA Press).

De la Hera, Alberto (1996): "Vitoria y Solórzano ante el problema de los justos títulos", en Homenaje al profesor Alfonso García-Gallo, 4:69-100 (Madrid, Universidad Complutense).

DoIG, James Conroy (2001): Aquinas's Philosophical Commentary on the Ethics: A Historical Perspective. New Synthese Historical Library; v. 50. Dordrecht (Boston, Kluwer Academic Publishers).

FALCón, Francisco (2017): "Representación hecha por el licenciado Falcón en Concilio provincial, sobre los daños y molestias que se hacen a los indios", En Informaciones acerca de la religión y gobierno de los Incas, editado por Horacio H. Urteaga y Carlos Alberto Romero, 134-76. Colección de libros y documentos referentes a la historia del Perú, t. 11. Lima.

Fuchs, Marko J. (2007): Gerechtigkeit als allgemeine Tugend: die Rezeption der aristotelischen Gerechtigkeitstheorie im Mittelalter und das Problem des ethischen Universalismus (Berlin, De Gruyter).

García Hernán, Enrique (2007): Consejero de ambos mundos: vida y obra de Juan de Solórzano Pereira (1575-1655). (Madrid, Fundación MAPFRE, Instituto de Cultura).

Gauthier, René Antoine, y Jean Yves Jolif (1970): Aristote: L'éthique à Nicomaque. 2e éd., avec Une introduction nouvelle. Université Catholique de Louvain (1835-1969). Institut supérieur de philosophie. Aristote; traductions et études (Louvain, Paris: Publications universitaires; Béatrice-Nauwelaerts).

Hanke, Lewis (1949): The Spanish Struggle for Justice in the Conquest of America (Philadelphia, University of Pennsylvania Press). 
Hoffmann, Tobias, Jörn Müller, y Matthias Perkams (2013): Aquinas and the Nicomachean Ethics (Cambridge, Cambridge University Press).

Jansen, Nils (2012): "Von der Restitutionslehre der Spanischen Spätscholastik zu einem europäischen Recht nichtvertraglicher Schuldverhältnisse?”, Rabels Zeitschrift fuer ausländisches und internationales Privatrecht, 76, No 4: pp. 921-946.

Las Casas, Bartolomé de. Obras completas. 10: Tratados de 1552. Editado por Ramón Hernández y Lorenzo Galmés Más (Madrid, Alianza Editorial, 1992).

Las Casas, Bartolomé de. Obras completas. 11,2: Doce dudas. Editado por Juan Bautista Lassègue (Madrid, Alianza Editorial, 1992).

Lohmann Villena, Guillermo (1970): "El licenciado Francisco Falcón (1521-1587). Vida, escritos y actuación en el Perú de un procurador de los indios", Anuario de Estudios Americanos, 27: pp. 131-194.

Massini Correas, Carlos Ignacio, y Joaquín García-Huidobro (2012): "Valoración e inclusión en el Derecho. La máxima 'Lex injusta non est lex' y la iusfilosofía contemporánea”, En Razón jurídica y razón moral: estudio sobre la valoración ética en el derecho, editado por Juan Cianciardo, Juan B Etcheverry, Joaquín García-Huidobro, Carlos I Massini Correas, y Pilar Zambrano, 117-145 (México, Porrúa-Universidad Austral).

Matienzo, Juan de, Gobierno del Perú: 1567. Editado por Guillermo Lohmann Villena. Travaux de l'Institut Français d'Études Andines 11. Lima: Institut Français d'Études Andines, 1967.

McCormick, Richard A (1978): "Ambiguity in Moral Choice", en Doing Evil to Achieve Good. Moral Choice in Conflict Situations, editado por Richard McCormick y Paul Ramsey: pp. 7-53. 1973 (Chicago, Loyola University Press).

Miranda, Alejandro (2017): "Consequentialism, the Action/Omission Distinction, and the Principle of Double Effect: Three Rival Criteria to Solve Vital Conflicts in Cases of Necessity", The American Journal of Jurisprudence, 62, No 2: 209-229.

Odon Lottin (1942): Psychologie et morale aux XIIe et XIIIe siècles (Louvain, Abbaye du Mont César).

Odonis, Geraldus. Expositio in Aristotelis ethicam. Italian books before 1601; roll 243, item 4. Venezia: Venezia, Simon de Lovere, for A. Torresanus, 1500.

Oresme, Nicole. Le livre de Ethiques d'Aristote. Editado por Albert D. Menut. Nueva York: G.E. Stecuert \& Co. Publishers, 1910.

Pereña, Luciano (1994): "Defensor oficial de la Corona”, En Juan de Solórzano Pereira, De Indiarum iure. Liber III: De retentione Indiarum, 19-61. Corpus Hispanorum de pace, 2. ser., v. 1 (Madrid, Consejo Superior de Investigaciones Científicas).

Pérez Amador Adam, Alberto (2011): De legitimatione imperii Indiae Occidentalis: la vindicación de la Empresa Americana en el discurso jurídico y teológico de las letras de los Siglos del Oro en España y los virreinatos americanos. Parecos y australes, No 5 (MadridFrankfurt am Main, Iberoamericana; Vervuert).

Poblete, José A (2020): “The Medieval Reception of Aristotle’s Passage on Natural Justice: The Role of Grosseteste's Latin Translation of Ethica Nicomachea", American Catholic Philosophical Quarterly, 94: pp. 211-238. 
Poblete, José A (2018): “Translation or Alteration? Grosseteste’s Latin Version of Aristotle's Account of Natural Justice", Journal of the History of Philosophy, 56, No 4: pp. 601-627.

Solórzano Pereira, Juan de. De Indiarum iure. Liber 2 [1]: De acquisitione Indiarum. Cap. 1-15. Editado por Carlos Baciero. Vol. II.1. 3 vols. Corpus Hispanorum de pace, Ser. 2, Vol. 5 (Madrid, Consejo Superior de Investigación Científicas, 1999).

Solórzano Pereira, Juan de. De Indiarum iure. Liber 2 [2]: De acquisitione Indiarum. Cap. 16-25. Editado por Carlos Baciero. Vol. II.2. 3 vols. Corpus Hispanorum de pace, Ser. 2, Vol. 7 (Madrid, Consejo Superior de Investigación Científicas, 2000).

Solórzano Pereira, Juan de. De indiarum iure. Liber I: De inquisitione Indiarum. Editado por Carlos Baciero. Vol. I. 3 vols. Corpus hispanorum de pace. Segunda serie 8 (Madrid, Consejo Superior de Investigaciones Científicas, 2001).

Solórzano Pereira, Juan de.. De Indiarum iure. Liber III: De retentione Indiarum. Editado por Carlos Baciero. Vol. III. 3 vols. Corpus Hispanorum de pace, 2. ser., v. 1 (Madrid, Consejo Superior de Investigaciones Científicas, 1994).

Tomás de Aquino. Summa theologiae. 3a ed. Torino: San Paolo, 1999.

Vargas Ugarte, Rubén (1951): Concilios limenses (1551-1772). Vol. I. 3 vols. (Lima, Tipografía Peruana).

Vitoria, Francisco de. Relectio de Indis o libertad de los indios. Editado por Luciano Pereña Vicente y José M. Pérez Prendes (Madrid, Consejo Superior de Investigaciones Científicas, 1967).

ZIEGLER, Karl-Heinz (1997): "Die rechtlichen Grundlagen der spanischen Herrschaft in Amerika nach Juan de Solórzano y Pereira”, Zeitschrift der Savigny-Stiftung für Rechtsgeschichte; Kanonistische Abteilung, 114: pp. 589-595. 
